\title{
The Domestic Violence during the COVID-19 Pandemic: Scoping Review
}

\author{
Luluk Rosida ${ }^{1}$, Intan Mutiara Putri ${ }^{1}$ (D), Komarudin Komarudin $^{2}$, Nurbita Fajarini ${ }^{1}$, Endang Koni Suryaningsih ${ }^{1}$ (D) \\ ${ }^{1}$ Midwifery Study Program, Faculty of Health Sciences, Universitas Aisyiyah Yogyakarta, Yogyakarta, Indonesia; ${ }^{2}$ Psychology \\ Study Program, Faculty of Social Economics and Humanities, Universitas Aisyiyah Yogyakarta, Yogyakarta, Indonesia
}

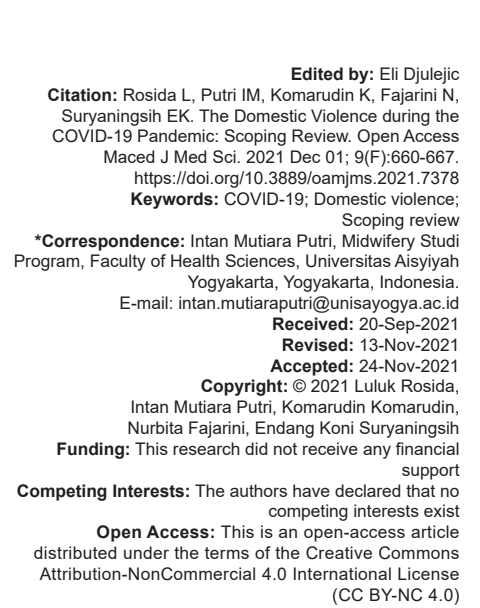

\section{Introduction}

At the end of December 2019, Severe Acute Respiratory Syndrome Coronavirus 2 (SARS-CoV-2) or often called COVID-19, was first detected in Wuhan, China, and quickly spread around the world [1], in approximately 3 months, to be precise on March 11, 2020, the World Health Organization announced COVID-19 as a global pandemic [2]. This forces governments in various countries to issue various policies related to the handling of COVID-19, ranging from "social distancing" to "lockdown [3]".

The COVID-19 pandemic has brought unexpected challenges in all sectors of life, from the social, economical to health sectors, particularly public health. One of the most worrying effects of COVID-19 is the increase in cases of domestic violence. During the lockdown, an increase in domestic violence cases occurred in several countries, including Argentina, Singapore, France, and Cyprus, respectively 25\%, $33 \%$, and $30 \%$ [4]. In addition, social and economic pressures due to reduced economic growth and impacts related to economic instability, job loss, changes in habits due to staying at home longer can increase the prevalence and severity of domestic violence [5], [6].

The "stay at home" policy, on the one hand, can reduce the spread of the COVID-19 virus. However, on the other hand, it can trigger conflict and increase the opportunity for perpetrators to commit violence, and make it difficult for victims to access assistance because victims and perpetrators spend more time together at home [7], [8]. According to Bouillon-Minois et al. [9], living with the same perpetrators of violence is even more dangerous than the COVID-19 pandemic, so that violence against women, especially domestic violence, is considered a "shadow pandemic" [10]. Domestic violence is physical, psychological; sexual violence used to control and dominates others, including violence against spouses, children, parents, and other household members [11].

Domestic violence is associated with increased injuries, disability, poorer health status, sleep disorders, chronic pain, substance abuse, reproductive disorders, gastrointestinal disorders, cardiovascular disease, chronic pelvic pain, urinary tract infections, and even death [12], [13], [14]. For example, in 2017, it was recorded that $58 \%$ of women were killed by a partner or family member [15]. In addition, domestic violence can 
also reduce work productivity, leading to an economic crisis [6], [16].

The increase in domestic violence cases and its short-term and long-term negative impacts must receive special attention from the authorities, including the community; preventive measures are essential to prevent these negative impacts. Although there are many publications about domestic violence during the COVID-19 pandemic, many are speculative. Therefore, this study aims to review the literature on domestic violence during the COVID-19 pandemic and its coping strategies.

\section{Methods}

The steps in preparing this scoping review were adapted from Preferred Reporting Items for Systematic Reviews and Meta-analyses Extension for Scoping Reviews (PRISMA-ScR) [17] to map domestic violence cases during the COVID-19 pandemic and their handling.

\section{Literature search strategy}

We determined keywords related to domestic violence during the COVID-19 pandemic. There were two categories of keywords, namely, keywords related to domestic violence ("domestic violence" OR "domestic abuse" OR "intimate partner violence" OR "marital abuse" OR "family violence" OR "family abuse") and keywords related to COVID-19 (COVID-19 OR "novel coronavirus" OR SARS-Cov-2 OR nCoV). The search for articles was carried out by entering a combination of keyword categories with the Boolean "AND" connector and using the whole text filter, published in 2019-2021 and English in the search fields in 4 electronic databases (PubMed, ScienceDirect, ProQuest, and Ebsco).

\section{Selection of articles}

Articles identified through our database were imported into the Zotero reference manager, and we deleted duplicate articles. All authors screened titles and abstracts to obtain articles that could potentially meet inclusion and exclusion criteria. The articles selected from the abstract selection were then accessed in full text for further assessment. All reviewers carried out discussions to obtain the final article used in this scoping review.

\section{Charting data}

Data extraction in a scoping review is referred to as data charting to provide an overview in the form of a summary of the article suitable for the scoping review [18]. We compiled charting data from the six articles, we used in this scoping review to describe the title briefly, author's name, year, country/location, destination, method, sample, and main results (Table 1). We applied thematic analysis steps [19] to get themes that were in line with the objectives of the scoping review. All authors repeatedly read each selected article, compile code, and classify themes. Discussions were carried out in determining the final theme.

\section{Results}

\section{The selected article description}

We identified 434 articles obtained from data search results and removed 36 duplicate articles. We performed a title screening of 398 articles and found 98 articles that might fit our criteria. The results of the abstract screening identified 15 articles that might meet the criteria for our full-text review. After conducting a full-text review, nine full-text articles that did not meet the criteria were excluded from the study, so that six articles were selected to be used in this scoping review (Figure 1).

\section{The characteristics of selected articles}

The six articles used in this scoping review were each from Iran [20], Ethiopia [21], Italy [22], Brazil [23], Australia [24], and Canada [25]. In addition, four articles focused on cases of domestic violence during the COVID-19 pandemic [21], [22], [24], [25], one article focused on cases of domestic violence in pregnant women during the COVID-19 pandemic [20], and one article focused on tackling domestic violence cases during the COVID-19 pandemic [23].

\section{Mapping themes}

There are six themes that we got related to domestic violence during the COVID-19 pandemic, namely: (1) The number of cases of domestic violence during the COVID-19 pandemic; (2) risk factors for domestic violence; (3) victims and perpetrators of domestic violence; (4) types of domestic violence; (5) impact of domestic violence; and (6) strategies for handling domestic violence during the COVID-19 pandemic (Figure 2).

\section{Discussion}

The number of domestic violence cases during the COVID-19 pandemic

Based on Table 2, the Domestic violence cases during the COVID-19 pandemic decreased to $55.84 \%$ from 
Table 1: Selected articles for scoping review

\begin{tabular}{lllll}
\hline No. & Article title/author/year & Country & Destination & Method \\
\hline 1. & Domestic violence and its relationship & Iran & This is to determine the prevalence & Cross-sectional \\
with quality of life in pregnant women & & $\begin{array}{l}\text { and correlation between quality of life } \\
\text { during the outbreak of COVID-19 }\end{array}$ & $\begin{array}{l}\text { and domestic violence in pregnant } \\
\text { somen during the COVID-19 }\end{array}$ \\
disease [20] & $\begin{array}{l}\text { womemic } \\
\text { BMC pregnancy and childbirth }\end{array}$ & pandemic & \\
& &
\end{tabular}

Sample
250 pregnant women at
Iran's 29-Bahman Tabriz
Hospital

Main results

As many as $35.2 \%$ of pregnant

As many as $35.2 \%$ of pregnant

women had experienced domestic violence

The quality of life of pregnant women who were exposed to domestic violence was lower (especially in the mental health domain) than pregnant women who were not exposed to domestic violence

2. Prevalence and Associated Factors of Intimate Partner Violence Among Married Women During COVID-19 Pandemic Restrictions: A Community-Based Study [21] Journal of Interpersonal Violence

3. Domestic violence detection amid the COVID-19 pandemic: the value of the WHO questionnaire in Emergency

Medicine [22]

QJM: monthly journal of the Association of Physicians
Ethiopia This is to determine the prevalence and factors related to violence against partners in women during the COVID-19 pandemic
Cross-sectional study community based

617 women who were married or living together

As many as 132 out of 589 (22.4\%) married women experienced at least one type of violence The predictor factors for domestic violence were: illiteracy; had an illiterate husband, had a husband who used drugs (alcohol, chat or smoke), lives in a society that was tolerant of violence

Italy 1. To determine the prevalence of domestic violence cases in patients who come to the Emergency Room of a large Italian Hospital in 2020

2. To assess the usefulness of the questionnaire of the WHO Multi-country Study on Women's Health and Domestic Violence against as a screening tool to revea hidden cases of domestic violence

Cross-sectiona study records in Emergency Room search with keywords ("violence," "assault," "trauma") to filter data and retrieve cases of violence in the period between 1 January and June 2 2020

(2) 75 women who came to the emergency room between July 14 and August 24, 2020

4. Domestic violence against women amidst the pandemic: coping strategies disseminated by digital media [23] Revista Brasileira De Enfermagem

5. Social isolation, time spent at home, financial stress and domestic violence during the COVID-19 pandemic [24] Trends and Issues in Crime and Criminal Justice

Brazil This is to find out about strategies for handling domestic violence in women that were disseminated through digital media at the beginning of the COVID-19 pandemic

\section{Australia To find out the impact of the COVID-19 Survey} pandemic on domestic violence cases

A documentary study with a from online pors sected 150 news items select from online portals $\begin{array}{ll}\text { based on the } & \text { comments on the socia }\end{array}$ Consolidated Criteria for Reporting Qualitative network twitter; 45 publications on official government pages; 42 publications on four

portals of third sector organizations Sample 15,000 women aged $\geq 18$ years. Sampling technique with Proportiona quota sampling

Domestic violence cases during the COVID-19 pandemic non-lockdown were $9.62 \%$ and increased to $21.74 \%$ during lockdown

The WHO Multi-country Studied

on Women's Health and Domestic Violence against questionnaire was excellent for screening for domestic violence

There were strategies for handling domestic violence, namely: 1. A strategy for communicating with women victims of domestic violence

2. Strategies in providing care and services for victims of domestic violence

3. A strategy to provide information to the public

The risk of recurrent or first-time violence was 1.3 and 1.4 times higher for women who had little contact with family and friends outside the home during the pandemic

Financial stress before the pandemic is a strong predictor of domestic violence

Canada To evaluate the impact before and Observational during the COVID-19 pandemic on the studies admission of emergency room patients for sexual violence and domestic violence

\author{
The medical records of \\ patients who came to \\ the Emergency Room \\ at Ottawa Hospital from Sexual violence cases and physical \\ March 4 to May 5, 2020 violence decreased respectively \\ (COVID-19 period) totaled $53,49 \%$, and $48.45 \%$, meanwhile, \\ 20,370 and 30,371 medical cases of psychological violence \\ records of emergency increased by $16.88 \%$ \\ room patients during \\ March 4 until May 5, 2018, \\ (period before COVID-19)
}

Table 2: Types of domestic violence during the COVID-19 pandemic

\begin{tabular}{llll}
\hline Author & Physical abuse (\%) & $\begin{array}{l}\text { Mental/Psychological } \\
\text { violence (\%) }\end{array}$ & Sexual violence (\%) \\
\hline Naghizadeh et al. [20] & 4,8 & 32.8 & 12.4 \\
Tadesse et al. [21] & 11 & 20 & 13.8 \\
Di Franco et al. [22] & 90.62 & 9,38 & - \\
Muldoon et al. [25] & 48.57 & 28.57 & 57.14 \\
\hline
\end{tabular}

77 cases in the period before COVID-19 (March 2018) to 34 cases in the COVID-19 period (March 2020) [25]. Although the number of domestic violence cases during the COVID-19 pandemic decreased compared to 3 years before the pandemic, the severity of physical violence by partners during the COVID-19 pandemic was higher [26].
The decrease in the number of domestic violence cases during the COVID-19 pandemic did not necessarily indicate the true situation, because domestic violence cases were like an iceberg phenomenon where reported cases were only a fraction of the actual cases [27]. Domestic violence is challenging to uncover because miss perception and stigmatization remain to exist in society. These stigmas and perceptions include: Domestic violence is often understood as a personal problem, not a social problem so that other parties should not interfere; consider violence as part of education (especially for adherents of a strongly patriarchal culture); the victim's weak bargaining position (wife/child) and financial dependence on the 


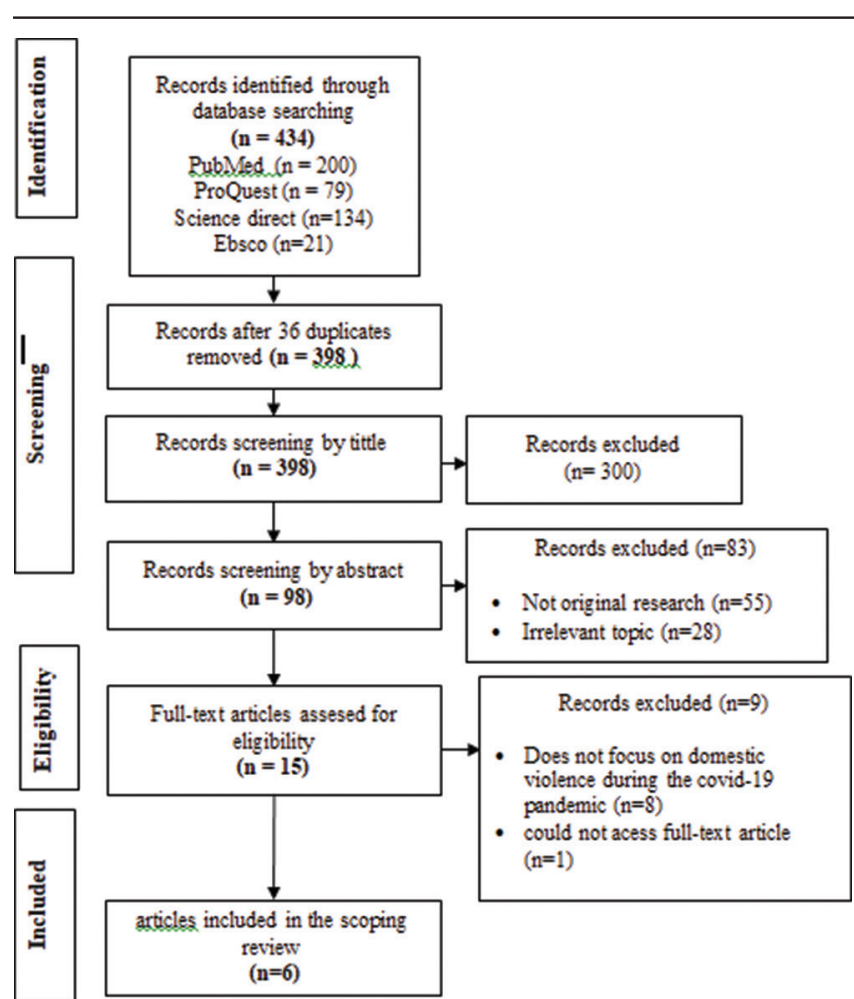

Figure 1: PRISMA flowchart for the selection of articles

perpetrator have made the victim silenced and even covered up the violence experienced because it is considered a family disgrace [28], [29].

The survey results in Portugal showed that during the COVID-19 pandemic, as many as $62.3 \%$ of domestic violence victims were reluctant to access assistance [30]. Victims of violence are reluctant to report because they think it is unnecessary, even if they are afraid to be blamed (victim-blaming) [30], [31].

The decrease in the number of domestic violence cases during the COVID-19 pandemic was also since victims and perpetrators spent more time together at home so that the mobility of victims was hampered, and it was not easy to access assistance [8]. On the other hand, more time spent with your partner during lockdown can lead to conflict and make perpetrators more flexible to commit violence [32]. Consequently, the severity of domestic violence during the lockdown is getting increase. Several countries experienced an increase in domestic violence cases during the lockdown, including France (30\%), Argentina (25\%), Cyprus (30\%), and Singapore (33\%) [4]. Even in Nigeria, the increase in domestic violence cases reached $56 \%$ [33]. Identically, our result shows the prevalence of domestic violence cases during lockdown increased by $12.12 \%$, from $9.62 \%$ to $21.74 \%$ [22].

\section{Risk factors for domestic violence}

We identified several risk factors related to domestic violence during the COVID-19 pandemic, among others: Illiterate women have an illiterate husband; married to drug users (alcohol, chat, or smoking); and living in a society that is tolerant of violence, financial stress, rarely having contact with family, and friends outside the home during the pandemic [21], [24].

According to Moreira and Pinto da Costa (2020), domestic violence is prone to occur in communities where violence is legalized as a way to resolve conflicts [34]. Women who live in societies tolerant of violence are up to 2.7 times more likely to get domestic violence [21].Women who experience financial stress are 1.8 times more likely to experience violence than women who do not experience financial stress [24]. In addition, the results of similar studies show that job and income loss, lots of time spent together, changing habits due to the less iterate husband; married to drug user domestic violence during the COVID-19 pandemic [6]. Victims and perpetrators of domestic violence.

Erpetrators of domestic violence ilar studies show that job and income loss, lots of time spent together, changing habits due to the less iterate husband; domestic violence was women (80-88\%, $57 \%$ ) [22], [25] where some of them were housewives (56.5-94.4\%) [20], [21]. Patriarchal culture, economic dependence, and emotional dependence are thought to be the causes of women being more vulnerable to becoming victims of domestic violence [28], [35].

Our findings show that 51, 43-66.67\% perpetrators of domestic violence were the victim's spouse (husband), followed by ex-partners, sons, and fathers. In contrast, for cases of domestic violence in boys, the perpetrators were older siblings, members. Family and people you knew in the family [22], [25]. Patriarchal beliefs contribute to the violent incidents that made men use violence to control women and show dominance [28], [36]. In contrast, economic and emotional dependence made women more likely to maintain relationships [35], it is risky to cause the victims to be trapped in a cycle of violence. They are challenging to break the cycle [37].

Naghizadeh et al. divided the severity of violence into three categories based on the frequency of violence, namely, mild violence (1itx) as many as $37.8 \%$, moderate violence (3rex) as many as $16.2 \%$, and severe violence $(>5 \times)$ as many as $25 \%$ [20]. We found that $22,67-67 \%$ of women had recurrent domestic violence [22], [24]. Inline, the previous research shows that $83 \%$ of male domestic violence perpetrators committed 2 times of repeated violence. There was one respondent who committed violence repeatedly up to 52 times [38].

\section{Types of domestic violence}

According to Tadesse et al., $22.4 \%$ of married women experienced at least one type of violence [21]. Naghizadeh et al. conducted a twin study. The result 


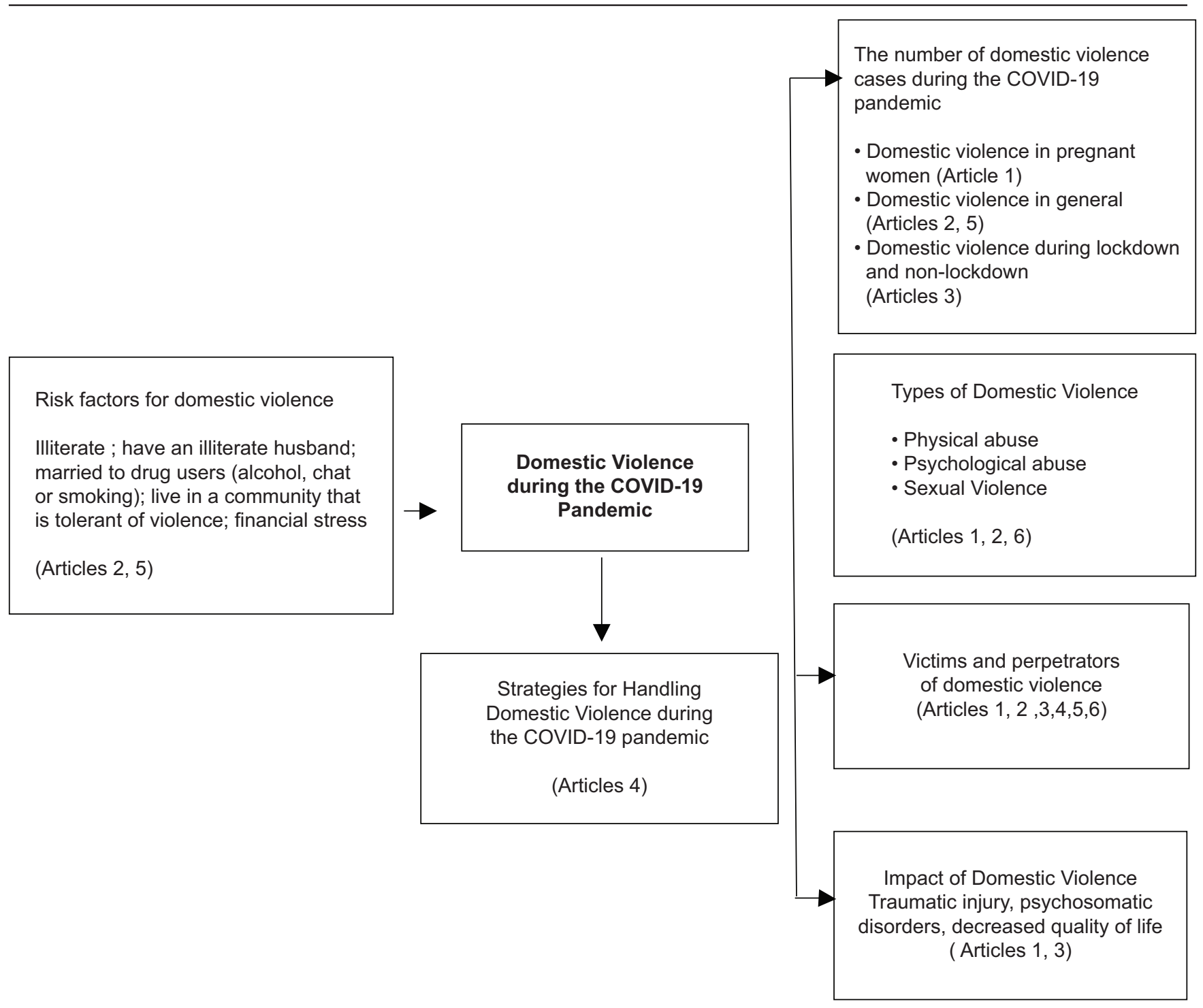

Figure 2: Mapping the scoping review theme

shows that about $23.2 \%$ of respondents experienced one type of violence, $10 \%$ two types, and $2 \%$ three types of violence [20], even according to Tadesse et al., $7.3 \%$ of women had experienced all types of domestic violence (physical, psychological, and sexual) [21]. Therefore, we did not find economic violence in this scoping review.

According to Muldoon et al. (2021), sexual violence and physical violence cases during the COVID-19 pandemic decreased from $53.49 \%$ to $48.45 \%$, while cases of psychological violence increased as many as $16.88 \%$. In contrast to these findings, Gosangi et al. (2021) found that the number of cases of physical violence during the COVID-19 pandemic increased by $27 \%$ from the previous year.

Results of research on domestic violence in pregnant women in Iran show that several acts of violence experienced by women based on the type of violence include emotional violence: limiting socializing, shouting/insulting, humiliating, and sexual violence: Forcing sexual intercourse. The term of physical violence includes throwing objects, pushing, pulling hair or arms [20]. According to Moreira and Pinto da Costa (2020), the perpetrator carried out restrictions on socializing to cut off contact with outsiders.

\section{The impact of domestic violence}

We identified several impacts related to domestic violence during the COVID-19 pandemic in the form of traumatic injuries (90.62\%), psychosomatic disorders $(9.38 \%)$, and decreased quality of life [20], [22]. The quality of life of pregnant women with domestic violence was lower, especially in physical health and mental health, than women who did not experience domestic violence, with the difference in scores of 3.24 and 15.43 , respectively [20]. The results of previous studies indicated that compared to women who had never experienced violence during pregnancy, the risk of perinatal and neonatal mortality was 2.59 and 2.37 times higher, respectively [39]. 
The violence against women affects their current health and their children's health in the future, including the emergence of intergenerational cycles of violence. The environment in which children develop significantly influences their physical and mental health [40]. Children who live in violent household environments feel emotionally insecure and have excessive anxiety and alertness, chaotic stress responses, and disturbed sleep comfort, impacting children's physical and psychological development [40]. Children under 3 years of age who witness domestic violence are at risk for impaired memory development and cognitive function at 5 years of age [41]. Domestic violence also affects the development of children's vocabulary and behavior problems, especially in boys [42].

The reactions of children exposed to violence are different, and this affects their social competence. Some children have low social skills, which affects their understanding and perspective on social signals in the environment. Some children share this attitude and believe that violence is the best way to manage conflict [43]. One thing that also needs to be considered regarding exposure to domestic violence in children is the occurrence of transgenerational violence. Children who see or experience domestic violence are more at risk of becoming victims or perpetrators of violence when they grow up [44]. The risk of becoming a victim of domestic violence is more remarkable for girls who are victims or who witness their mothers as victims of domestic violence. In contrast, the risk of becoming perpetrators of violence is more excellent for boys who experience or see their fathers committing domestic violence.

The role of various parties is needed to prevent domestic violence to create a child-friendly environment and break the cycle of violence between generations so that the lives of future generations will be better.

\section{Strategies for handling domestic violence during the COVID-19 pandemic}

Women are a population that is prone to violence, so great support is needed by women during this pandemic. Development and implementation alternative services such as telephone or online consultations, telemedicine, and training on early detection of domestic violence for health workers are urgently needed during this pandemic [45].

Other scholar identify three strategies for handling case of domestic violence during pandemic, including [23]:

\section{Strategy to maintain communication with} victims of domestic violence

Social restrictions during the COVID-19 pandemic limited our space, including with regard to reporting access for victims of domestic violence.
Strategies can be implemented to overcome this by facilitating toll-free complaint services; through internetbased applications (e.g., WhatsApp); homepage; and service map. The implementation of this strategy is expected to facilitate reporting and communication access for victim monitoring.

\section{Strategies for handling services for domestic} violence cases

Several services related to handling cases of domestic violence during a pandemic are needed, namely: Provision of shelters, psychological consultation (through telephone or virtual) online-based services at the policy office (report registration, case progress as well as emergency protection requests). Remote Justice System, Legislative system (formation of working groups related to contingency planning and draft laws).

\section{Strategies for providing information to the \\ public}

Strategies that can be implemented include the dissemination of information related to domestic violence during a pandemic through booklets and virtual campaigns; empowerment of third parties (neighbors) for reporting cases. This activity aims to educate the community to change their mindset that domestic violence is a social problem that requires joint handling.

Efforts to handle domestic violence during the COVID-19 pandemic are expected to focus on physical and mental health and economic empowerment so that women can be economically independent so that they no longer need to depend on domestic violence actors.

\section{Conclusion}

COVID-19 impacts domestic violence cases, where most victims are women, and most of them experience recurrent domestic violence. The pandemic has an impact on reducing face-to-face intensity. The role of social media and online-based services (hotlines, homepages, and WhatsApp) is needed to provide information and make it easier for victims to access services. The majority of the articles in this scoping review are quantitative research. We recommend that future research be examined deeper into the understanding, experiences, and needs of victims and perpetrators of domestic violence during the COVID-19 pandemic, including the roles of crosssectors and obstacles experienced in handling domestic violence in the future. 


\section{References}

1. Kong WH, Li Y, Peng MW, Kong DG, Yang XB, Wang L, et al. SARS-CoV-2 detection in patients with influenza-like illness. Nat Microbiol. 2020;5(5):675-8. https://doi.org/10.1038/ s41564-020-0713-1 PMid:32265517

2. World Health Organization. WHO Director-general's Opening Remarks at the Media Briefing on COVID-19-11 March 2020. 2020. Available from: https://www.who.int/director-general/ speeches/detail/who-director-general-s-opening-remarksat-the-media-briefing-on-covid-19---11-march-2020 [Last accessed on $2021 \mathrm{Feb}$ 12].

3. Holshue ML, DeBolt C, Lindquist S, Lofy KH, Wiesman J, Bruce $\mathrm{H}$, et al. First case of 2019 novel coronavirus in the United States. N Engl J Med. 2020;382(10):929-36. https://doi. org/10.1056/NEJMoa2001191

\section{PMid:32004427}

4. UN Women. Issue Brief: COVID-19 and Ending Violence Against Women and Girls, Digital Library: Publications. UN Women; 2020. Available from: https://www.unwomen.org/digital-library/ publications/2020/04/issue-brief-covid-19-and-ending-violenceagainst-women-and-girls [Last accessed on 2020 Dec 31].

5. Fawole OI, Okedare OO, Reed E. Home was not a safe haven: Women's experiences of intimate partner violence during the COVID-19 lockdown in Nigeria. BMC Womens Health. 2021;21(1):32. https://doi.org/10.1186/s12905-021-01177-9 PMid:33472627

6. Sharma A, Borah SB. Covid-19 and domestic violence: An indirect path to social and economic crisis. J Fam Violence. 2020;28:1-7. https://doi.org/10.1007/s10896-020-00188-8 PMid:32836737

7. Hsu LC, Henke A. COVID-19, staying at home, and domestic violence. Rev Econ Househ. 2020;20:1-11. https://doi. org/10.1007/s11150-020-09526-7

PMid:33235551

8. Leslie E, Wilson R. Sheltering in place and domestic violence: Evidence from calls for service during COVID-19. J Public Econ. 2020;189:104241.

9. Bouillon-Minois JB, Clinchamps M, Dutheil F. Coronavirus and quarantine: Catalysts of domestic violence. Violence Against Women. 2020;26:1-3.

10. UN Women. The Shadow Pandemic: Violence Against Women During COVID-19. UN Women; 2020. Available from: https:// www.unwomen.org/en/news/in-focus/in-focus-gender-equalityin-covid-19-response/violence-against-women-during-covid-19 [Last accessed on 2020 Dec 31].

11. Huecker MR, King KC, Jordan GA, Smock W. Domestic violence. In: StatPearls. Treasure Island, FL: StatPearls Publishing; 2021. Available from: https://www.ncbi.nlm.nih.gov/ books/NBK499891 [Last accessed on 2020 Mar 1].

12. Chandan JS, Thomas T, Bradbury-Jones C, Taylor J, Bandyopadhyay S, Nirantharakumar K. Risk of cardiometabolic disease and all-cause mortality in female survivors of domestic abuse. J Am Heart Assoc. 2020;9(4):e014580. https://doi. org/10.1161/JAHA. 119.014580

PMid:32063124

13. El-Serag R, Thurston RC. Matters of the heart and mind: Interpersonal violence and cardiovascular disease in women. J Am Heart Assoc. 2020;9(4):e015479. https://doi.org/10.1161/ JAHA.120.015479 PMid:32063117

14. Rakovec-Felser Z. Domestic violence and abuse in intimate relationship from public health perspective. Health Psychol Res.
2014;2(3):1821. https://doi.org/10.4081/hpr.2014.1821 PMid:26973948

15. Vienna. UNODC, Global Study on Homicide 2019. UNODC; 2019. Available from: https://www.unodc.org/documents/dataand-analysis/gsh/Booklet_5.pdf [Last accessed on 2020 Jun 5].

16. CDC. Preventing Intimate Partner Violence, Violence Prevention, Injury Center. CDC; 2020. Available from: https://www.cdc.gov/ violenceprevention/intimatepartnerviolence/fastfact.html [Last accessed on $2021 \mathrm{Feb} 13]$.

17. Tricco AC, Lillie E, Zarin W, O'Brien KK, Colquhoun $\mathrm{H}$, Levac $\mathrm{D}$, et al. PRISMA extension for scoping reviews (PRISMA-ScR): Checklist and explanation. Ann Intern Med. 2018;169(7):467-73. https://doi.org/10.7326/M18-0850 PMid:30178033

18. Peters M, Godfrey C, McInerney P, Munn Z, Tricco A, Khalil H. Scoping reviews (2020 version). In: Aromataris E, Munn Z, editors. JBI Manual for Evidence Synthesis. Ch. 11. Australia: Joanna Briggs Institute; 2020. Available from: https://www. synthesismanual.jbi.global [Last accessed on 2020 Dec 1]. https://doi.org/10.46658/JBIMES-20-12

19. Braun V, Clarke V. Using thematic analysis in psychology. Qual Res Psychol. 2006;3(2):77-101.

20. Naghizadeh S, Mirghafourvand M, Mohammadirad R. Domestic violence and its relationship with quality of life in pregnant women during the outbreak of COVID-19 disease. BMC Pregnancy Childbirth. 2021;21(1):88.

21. Tadesse AW, Tarekegn SM, Wagaw GB, Muluneh MD, KassaAM Prevalence and associated factors of intimate partner violence among married women during COVID-19 pandemic restrictions: A community-based study. J Interpers Violence. 2020;35:1-19. https://doi.org/10.1177/0886260520976222 PMid:33289437

22. Di Franco M, Martines GF, Carpinteri G, Trovato G, Catalano D. Domestic violence detection amid the COVID-19 pandemic: The value of the WHO questionnaire in emergency medicine. QJM. 2021;114(9):637-41. https://doi.org/10.1093/qjmed/hcaa333 PMid:33377948

23. Fornari LF, Lourenço RG, de Oliveira RN, Santos DL, Menegatti MS, da Fonseca RM. Domestic violence against women amidst the pandemic: Coping strategies disseminated by digital media. Rev Bras Enferm. 2021;74(1):e20200631. https://doi.org/10.1590/0034-7167-2020-0631 PMid:33533806

24. Morgan A, Boxall $H$. Social isolation, time spent at home, financial stress and domestic violence during the COVID-19 pandemic. Trends Issues Crime Crim Just. 2020;609:1-18.

25. Muldoon KA, Denize KM, Talarico R, Fell DB, Sobiesiak A, Heimerl M, et al. COVID-19 pandemic and violence: Rising risks and decreasing urgent care-seeking for sexual assault and domestic violence survivors. BMC Med. 2021;19(1):20. https:// doi.org/10.1186/s12916-020-01897-z

PMid:33541357

26. Gosangi B, Park H, Thomas R, Gujrathi R, Bay CP, Raja AS, et al. Exacerbation of physical intimate partner violence during COVID-19 pandemic. Radiology. 2021;298(1):E38-45. https:// doi.org/10.1148/radiol.2020202866 PMid:32787700

27. Gracia E. Unreported cases of domestic violence against women: Towards an epidemiology of social silence, tolerance, and inhibition. J Epidemiol Community Health. 2004;58(7):536-7. https://doi.org/10.1136/jech.2003.019604 PMid:15194711

28. Sikweyiya Y, Addo-Lartey AA, Alangea DO, Dako-Gyeke P, Chirwa ED, Coker-Appiah D, et al. Patriarchy and genderinequitable attitudes as drivers of intimate partner violence 
against women in the central region of Ghana. BMC Public Health. 2020;20(1):682.

29. Tonsing JC, Tonsing KN. Understanding the role of patriarchal ideology in intimate partner violence among South Asian women in Hong Kong. Int Soc Work. 2019;62(1):161-71.

30. Gama A, Pedro AR, de Carvalho MJ, Guerreiro AE, Duarte V, Quintas J, et al. Domestic violence during the COVID-19 pandemic in Portugal. PJP. 2020;38(1):32-40.

31. Heron RL, Eisma MC. Barriers and facilitators of disclosing domestic violence to the healthcare service: A systematic review of qualitative research. Health Soc Care Community. 2021;29(3):612-30. https://doi.org/10.1111/hsc.13282 PMid:33440034

32. Perez EM, Carrara H, Bourne L, Berg A, Swanevelder S, Hendricks MK. Massage therapy improves the development of HIV-exposed infants living in a low socio-economic, peri-urban community of South Africa. Infant Behav Dev. 2015;38:135-46. https://doi.org/10.1016/j.infbeh.2014.12.011 PMid:25645599

33. UN Nigeria. Gender-based Violence in Nigeria During the COVID-19 Crisis: The Shadow Pandemic (Brief, 4 May 2020), United Nations in Nigeria; 2020. Available from: https://www. nigeria.un.org/en/45324-gender-based-violence-nigeria-duringcovid-19-crisis-shadow-pandemic-brief-4-may-2020 [Last accessed on 2020 Jun 13].

34. Moreira DN, Pinto da Costa M. The impact of the Covid-19 pandemic in the precipitation of intimate partner violence. Int $\mathrm{J}$ Law Psychiatry. 2020;71:101606.

35. Bornstein RF. The complex relationship between dependency and domestic violence: Converging psychological factors and social forces. Am Psychol. 2006;61(6):595-606. https://doi. org/10.1037/0003-066X.61.6.595

PMid:16953747

36. Mazibuko NC. Checkmating the mate: Power relations and domestic violence in a South African township. South Afr Rev Sociol. 2017;48(2):18-31.
37. Both LM, Favaretto TC, Freitas LH. Cycle of violence in women victims of domestic violence: Qualitative analysis of OPD 2 interview. Brain Behav. 2019;9(11):e01430. https://doi. org/10.1002/brb3.1430 PMid:31588692

38. Hester M. Who does what to whom? Gender and domestic violence perpetrators in English police records. Eur $\mathrm{J}$ Criminol. 2013;10(5):623-37.

39. Sarkar NN. The cause and consequence of domestic violence on pregnant women in India. J Obstet Gynaecol. 2013 Apr;33(3):250-3. https://doi.org/10.3109/01443615.2012. 747493

PMid:23550851

40. Olusegun EA. Domestic violence, risky family environment and children: A bio-psychology perspective. Int J Psychol Couns. 2014;6(8):107-18.

41. Gustafsson HC, Coffman JL, Harris LS, Langley HA, Ornstein PA, Cox MJ. Intimate partner violence and children's memory. Journal of Family Psychology. 2013;27(6):937-44. https://doi.org/10.1037/a0034592 PMid:24188084

42. Berthelon M, Contreras D, Kruger D, Palma MI. Violence during early childhood and child development. Child Dev. 2018;55:31.

43. Majali SA, Alsrehan $\mathrm{H}$. The impact of family violence on the social and psychological development of the child. Utopía Praxis Latinoam. 2019;24(5):199-207.

44. Camilleri LS. The Intergenerational Transmission of Violence: A Systematic Review; 2014. Available from: https://www. um.edu.mt/library/oar/handle/123456789/2323 [Last accessed on 2021 Nov 08]

45. Barbara G, Facchin F, Micci L, Rendiniello M, Giulini P, Cattaneo C, et al. COVID-19, lockdown, and intimate partner violence: Some data from an Italian service and suggestions for future approaches. J Womens Health (Larchmt). 2020;29(10):1239-42. https://doi.org/10.1089/jwh.2020.8590 PMid:33006492 